\title{
Morphological and Genetic Divergences in a Coral Reef Damselfish, Pomacentrus coelestis
}

\author{
B. Frédérich · S.-Y. V. Liu · C.-F. Dai
}

Received: 23 October 2011/Accepted: 26 December 2011/Published online: 13 January 2012

(C) Springer Science+Business Media, LLC 2012

\begin{abstract}
Population differentiation is one of the main topics in evolutionary biology. Except the exploration of color variation, few studies focused on morphological divergences among populations of coral reef fishes. In this work, we studied morphological and genetic differentiation among populations of the damselfish, Pomacentrus coelestis, in the northwestern Pacific Ocean. The shapes of the mandible and the premaxilla were explored using geometric morphometric methods and the genetic structure was investigated using microsattelites. Various tests revealed significant shape variation among most $P$. coelestis populations for both skeletal units. Morphological variation of the mandible accompanies a genetic break between populations of mainland Japan and Okinawa-Taiwan. However, Mantel and Procrustes tests revealed no congruence between morphological and genetic structures. We illustrate that phenotypic plasticity and adaptive divergence are potential evolutionary mechanisms underlying shape difference among $P$. coelestis populations. An ecomorphological approach suggests that various diet could be related to shape variation of oral jaws.
\end{abstract}

Keywords Pomacentridae - Geometric morphometrics · Jaw shape - PROTEST - Phenotypic plasticity - Adaptive divergence

B. Frédérich and S.-Y. V. Liu contributed equally to this study.

B. Frédérich $(\bowtie)$

Laboratoire de Morphologie Fonctionnelle et Evolutive, Institut de Chimie (B6c), Université de Liège, Liege, Belgium e-mail: bruno.frederich@ulg.ac.be

S.-Y. V. Liu · C.-F. Dai

Institute of Oceanography, National Taiwan University,

Taipei, Taiwan

\section{Introduction}

Variation is the source of evolutionary change and population differentiation is essential in the speciation process (Turelli et al. 2001). As suggested by Garnier et al. (2005), it is essential to study the relative influence of the evolutionary forces (e.g. gene flow, natural selection, genetic drift) that interact to produce a given pattern of differentiation and variability with a wide array of markers, such as genetic, morphological, physiological or behavioral markers.

The use of genetic markers in biogeographic studies is now very common for terrestrial and aquatic animals to reveal population structures (e.g. Planes 1993; Michaux et al. 2003; Bunje 2005). Morphological markers are commonly used too and it was shown that morphology may exhibit clear patterns of differentiation where molecular markers failed to detect population structure (e.g. Nice and Shapiro 1999). Many studies have also tested the congruence between morphology and genetics and the results vary according to the biological models. For example, shape variation of the pronotum and the aedeagus in the ground beetle, Carabus solieri reflected the underlying population genetic structure, strengthening the conclusions about the geographical pattern of differentiation (Garnier et al. 2005). On the other hand, a geometric morphometric study of the crania in the Karoo bush rat, Myotomys unisulcatus failed to support the genetic groupings (Edwards et al. 2011). Various factors can lead to a discordance between phenotypic traits and genetic data sets: elevated molecular lineage diversification, phenotypic plasticity or rapid morphological divergence under environmental factors (Rocha et al. 2005; Schultz et al. 2007).

The life history of most coral reef fishes is divided into two distinct stages (Sale 1980; Leis 1991): a relatively sedentary adult and juvenile stage, and a planktonic egg 
and/or larval stage capable of dispersing. According to their biology, the prevailing view is that coral reef fish populations are highly open and interconnected (Sale 1991). However, recent findings of local retention of reef fish larvae or restricted larval dispersal (Jones et al. 1999, 2005) concordant with reduced gene flow implies the possibility that parapatric populations can evolve divergently under different environmental factors. For example, Rocha et al. (2005) highlighted phylogenetic breaks between adjacent populations of Halichoeres bivittatus living in ecologically distinct habitats (tropical vs. subtropical habitats).

Various studies have tested the congruence between color pattern and genetic structure in coral reef fishes and the results are highly variable. Some species of angelfishes, butterflyfishes and damselfishes are known to exhibit color differences in the absence of molecular divergence (Bell et al. 1982; McMillan et al. 1999; Bernardi et al. 2002; Bowen et al. 2006; Schultz et al. 2007), but in some cases, concordance between coloration and genetic divergence can also be found (Rocha 2004; Drew et al. 2010). The color pattern is probably the most studied phenotypic trait in phylogeographic studies testing the presence of possible incipient speciation of coral reef fishes. Most of these phylogeographic studies tried to determine whether color morphs correspond to distinct clades. Conversely, few studies have explored the geographic variation of other morphological characters in these reef fishes. For example, Bell et al. (1982) showed variations of some meristic characters (i.e. fin-rays counts, size) among populations of the clownfish, Amphiprion clarkii. Molina et al. (2006) highlighted body shape variation between continental and island populations of a damselfish, Abudefduf saxatilis. To our knowledge, geographic variation of skull shape has never been tested in coral reef fishes although it has been extensively studied in freshwater (e.g. Streelman et al. 2007) and terrestrial (e.g. Alibert et al. 2001; Cardini et al. 2007) animals. Studies dealing with genetic signals underlying skull shape variations in cichlid fish (e.g. Albertson et al. 2005; Parsons and Albertson 2009) and related comparative genomic analysis (e.g. Loh et al. 2008) set out new perspectives in the interpretation of skull shape variation among fish populations. In rapidly diversifying lineages such as the cichlid fishes of the African Great Lakes, genetically determined divergence in form might be observed without a more global genetic signature (e.g. neutral microsatellite loci) (Loh et al. 2008). In other words, no congruence between population structure assessed by neutral loci and geographic skull shape variation assessed by morphometric methods may clearly reveal evolutionary mechanisms such as plasticity and adaptation. On the other hand, genetic drift would be a more likely explanation if the concordance between morphological and neutral genetic markers is present.
The neon damselfish, Pomacentrus coelestis, is widely distributed in the Indo-West Pacific region (Allen 1991) and is particuliarly abundant in coral reef habitats between Taiwan and Japan. This species feeds mainly on planktonic copepods (Kuo and Shao 1991). Variation of reproductive traits was already highlighted between $P$. coelestis populations from the Ryukyu Islands and mainland Japan (Kokita 2003, 2004), and a recent study of Liu et al. (2008) suggested these variations are likely associated with genetic divergences. However the geographic variation of phenotypic traits, such as morphology or skeletal shapes, was never studied. In addition, the oral jaws (mandible and premaxilla) shape variation was found to have a strong relationship with trophic evolution in damselfishes (Frédérich et al. 2008; Cooper and Westneat 2009; Frédérich and Vandewalle 2011). So, rapid morphological divergences in oral jaws among populations might be expected under various trophic factors (e.g. competition for diet, availability of preys) in the absence of population structure.

Under the sampling scheme of Liu et al. (2008), the morphological analysis of mandible and premaxilla and population genetic analyses were conducted to (1) test for shape variations of the buccal jaws among various populations of $P$. coelestis, (2) test for congruence between morphological and genetic population structure and (3) investigate the implications of congruencies and/or discordances of patterns of population structure from morphological and genetic markers for the phylogeography of P. coelestis.

\section{Materials and Methods}

\section{Samples and Data Collection}

A total of 177 adults of $P$. coelestis were collected with barrier nets by scuba diving at eight localities in southern Japan and Taiwan (Fig. 1). The sampling sites, from north to south, were Kominato in Chiba Prefecture (KN), Okinoshima Island in Fukuoka Prefecture (OS), Funakoshi in Ehime Prefecture (FS), Bohnotsu in Kagoshima Prefecture (BS), Tanegashima Island in Kagoshima Prefecture (TN), Nakanoshima Island in Kagoshima Prefecture (NS), Sesoko Island in Okinawa Prefecture (SK) (all in Japan), and Tiaoshi (TS) in southern Taiwan. Sampling localities were exactly the same as those described in Liu et al. (2008). Tissue samples were collected as fin clips preserved in EtOH. Then fish were preserved in $70 \%$ alcohol. The method for DNA extraction was modified from that described in Liu et al. (2005). Sample sizes ranged from 15 to 30 according to the locality (Table 1), and standard lengths $(\mathrm{SL}=$ length from the tip of the snout to the 


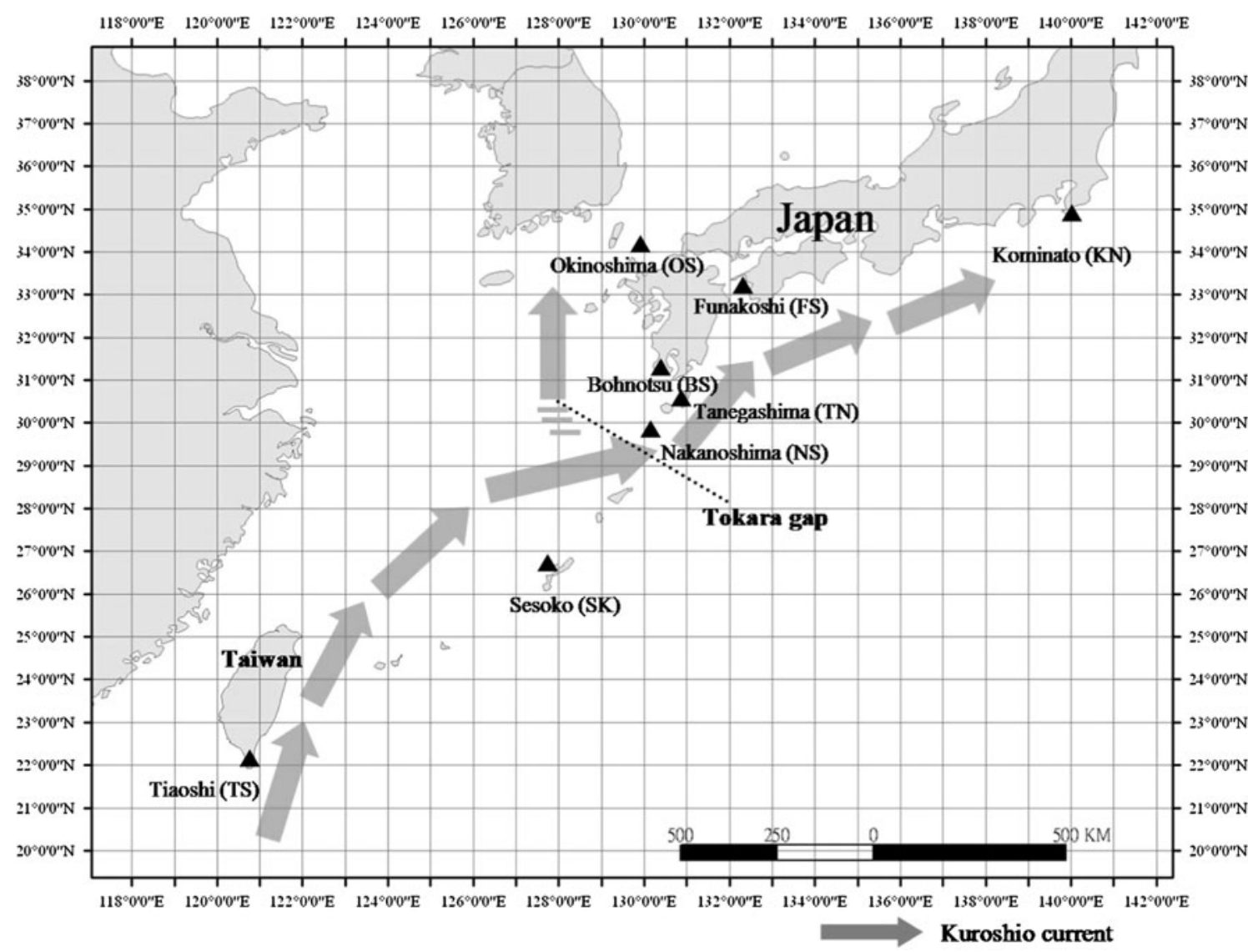

Fig. 1 Map showing the sampling localities of P. coelestis populations in Taiwan and Japan. The solid arrows indicate the pathway of the Kuroshio Current and the dash line indicates the Tokara gap

posterior edge of the caudal peduncle) ranged $40-70 \mathrm{~mm}$. The premaxillary bones and the mandibles (i.e. oral jaws) of individuals from the five most disperse localities (Fig. 1; Table 1) were dissected and then cleared and stained with alizarin red S (Taylor and Van Dyke 1985).

\section{Microsatellite Genotyping}

Genomic DNAs extracted from 177 individuals were used to perform microsatellite genotyping. Five microsatellite loci were applied including POM3, POM25 (Miller-Sims et al. 2005), AC1578 (Liu et al. 2007) and two novel loci Pom2269 (Pom2269F: 5'-CAGCTCTGTG TGTGTTTAA TGC-3', Pom2269R: 5'-CACCCAGCCACC ATATTAA C-3'); Pom2416 (Pom2416F: 5'-GGACCATTCAACCTT GGGTA-3', Pom2416R: 5'-GGaGATGAG CAAGTGT GCTG- $3^{\prime}$ ). The annealing temperatures of Pom2269 and Pom2416 were identical which was $55^{\circ} \mathrm{C}$. Standard PCR reaction was $25 \mathrm{ng}$ of each primer, $1.5-3 \mathrm{mM} \mathrm{MgCl}_{2}, 10 \times$ PCR buffer, $2.5 \mathrm{nM}$ dNTPs, 1 unit of Taq DNA polymerase, and 2-5 ng DNA in a $25 \mu \mathrm{l}$ reaction volume with a cycling profile of $2 \mathrm{~min}$ at $94^{\circ} \mathrm{C}$ for the first cycle, followed by 34 cycles at $95^{\circ} \mathrm{C}(30 \mathrm{~s}), 50-55^{\circ} \mathrm{C}(20 \mathrm{~s})$, and $70^{\circ} \mathrm{C}$
(30 s). Primers were labeled with fluorescent dye (FAM and HEX), and PCR products were visualized and sized by automated detection with gel electrophoresis using ABI3700 automated sequencer then analyzed by Peak Scanner Software 1.0 (Applied Biosystems, USA).

\section{Microsatellite Analyses}

Allele frequencies, mean allelic richness, expected $\left(H_{E}\right)$, observed $\left(H_{O}\right)$ heterozygosity per locus and linkage disequilibrium test with 1,000 permutations between all pairs of loci were computed by Arlequin 3.0 (Excoffier et al. 2005). Allele frequencies, mean allelic richness, $H_{E}$ and $H_{O}$ heterozygosity per locus were computed by FSTAT 2.9.3 (Goudet 1995). Hardy-Weinberg expectation for each locus and populations were tested by the Markov-chain method with the program GENEPOP version 3.3 (Raymond and Rousset 1995; available at http://wbiomed. curtin.edu.au/genepop), which implements Fisher's exact tests for multiple alleles (Guo and Thompson 1992). A Neighbour-Joining (NJ) tree was constructed by MEGA 4 (Tamura et al. 2007) based on the Nei's $\left(D_{A}\right)$ genetic distance (Nei et al. 1983) calculated by Micosatellite 
Table 1 Geographic information, abbreviations and samples sizes for genetic $\left(N_{m o l}\right)$ and morphometric analysis $\left(N_{\text {mand }}\right.$, mandible shape analysis, $N_{\text {premax }}$, premaxilla shape analysis) of $P$. coelestis

\begin{tabular}{|c|c|c|c|c|c|c|}
\hline Abbreviation & Locality & Latitude & Longitude & $N_{m o l}$ & $N_{\text {mand }}$ & $N_{\text {premax }}$ \\
\hline $\mathrm{KN}$ & Kominato, Chiba, Japan & $35.04^{\circ} \mathrm{N}$ & $140.07^{\circ} \mathrm{E}$ & 21 & 20 & 21 \\
\hline OS & Okinoshima Island, Fukuoka, Japan & $34.09^{\circ} \mathrm{N}$ & $130.04^{\circ} \mathrm{E}$ & 29 & 18 & 19 \\
\hline FS & Funakoshi, Ehime, Japan & $33.02^{\circ} \mathrm{N}$ & $132.16^{\circ} \mathrm{E}$ & 15 & - & - \\
\hline BS & Bohnotsu, Kagoshima, Japan & $31.09^{\circ} \mathrm{N}$ & $131.09^{\circ} \mathrm{E}$ & 23 & 20 & 20 \\
\hline $\mathrm{TN}$ & Tanegashima Island, Kagoshima, Japan & $30.43^{\circ} \mathrm{N}$ & $130.59^{\circ} \mathrm{E}$ & 30 & - & - \\
\hline NS & Nakanoshima Island, Kagoshima, Japan & $29.30^{\circ} \mathrm{N}$ & $129.31^{\circ} \mathrm{E}$ & 22 & - & - \\
\hline SK & Sesoko Island, Okinawa, Japan & $26.23^{\circ} \mathrm{N}$ & $127.31^{\circ} \mathrm{E}$ & 17 & 16 & 17 \\
\hline $\mathrm{TS}$ & Tiaoshi, Pingdong, Taiwan & $21.57^{\circ} \mathrm{N}$ & $120.46^{\circ} \mathrm{E}$ & 20 & 14 & 14 \\
\hline Total & & & & 177 & 88 & 91 \\
\hline
\end{tabular}

analyser (MSA) (Dieringer and Schlotterer 2003). In addition, the pairwise $F_{S T}$ values between eight populations were calculated by FSTAT 2.9.3 (Goudet 1995) and the significance between each comparison pair was evaluated through 1,000 permutation procedures.

\section{Morphometric Methods and Statistics}

To quantify the morphology of the mandible and the premaxilla, we used geometric morphometric methods (Bookstein 1991; Rohlf and Marcus 1993; Adams et al. 2004). These methods quantify the shape of anatomical objects from the coordinates of repeatable locations, after the effects of non-shape variation are mathematically held constant. First, the locations of 13 and 6 homologous landmarks (LM) were recorded from the left lateral view of the mandible and the premaxilla, respectively using TpsDig (Version 1.40) (Fig. 2). All landmarks are described in Frédérich et al. (2008) and the various steps taken to reduce measurement errors are detailed in Frédérich and Sheets (2010). For each skeletal unit, all specimens were optimally aligned using a generalized procrustes superimposition (Rohlf and Slice 1990), the grand mean (i.e. the consensus of all specimens) was calculated, and shape variables were then generated as partial warp scores (PWs) including both uniform and nonuniform components (Bookstein 1991; Rohlf 1993). These shape variables were used in all multivariate analysis. Thin plate spline functions (Bookstein 1991) were used to depict results of ordinations and regression models. The centroid size (CS) of each structure was computed as the square root of the sum of the squares of the distances from all LMs to their centroid (Bookstein 1991).

Shapiro-Wilks tests revealed a normal distribution of SL and CS within every sampled population (results not shown). So a one-way analysis of variance (ANOVA) was performed to check size variation across populations and these tests revealed significant differences among populations for SL and CS of both skeletal units $(P<0.01)$.

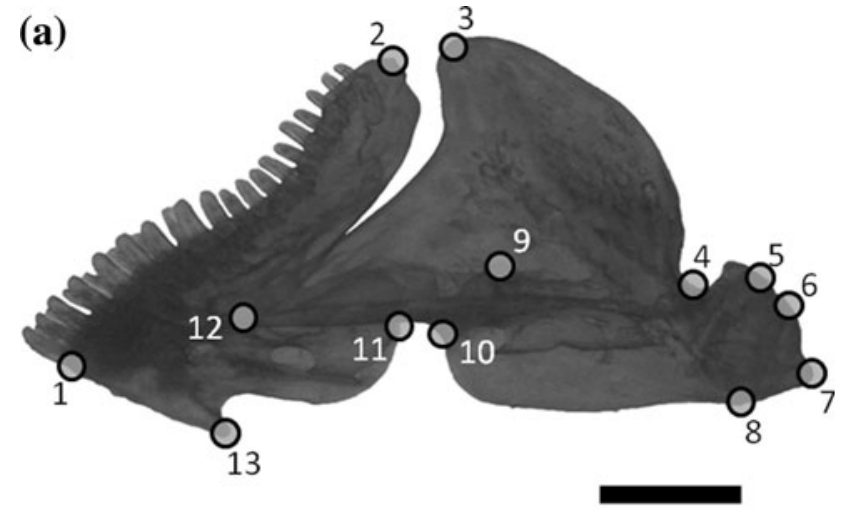

(b)

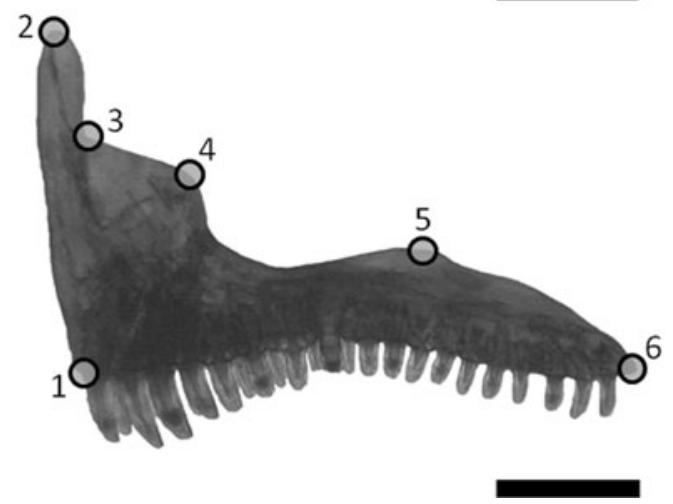

Fig. 2 a Mandible and b premaxilla of $P$. coelestis illustrating the various landmarks (LMs) used for the geometric morphometric analyses. All LMs are described in Frédérich et al. (2008). Scale bars $=1 \mathrm{~mm}$

Knowing that shape variation can be explained by size variation [i.e. allometry (Klingenberg 1998)], we used regression to correct the effect of size. Size correction of shape data was performed by a linear regression of all shape variables (PWs) on CS, and the residuals of regressions will be used as new datasets in the statistical analyses. For simplicity, these new datasets will be named "size-corrected shape variables" in the following analyses.

We performed a number of statistical tests to examine patterns of morphological divergences among populations. 
First, multivariate analysis of variance (MANOVA) and canonical variate analysis (CVA) were performed on sizecorrected shape variables for comparing shape of both skeletal elements among populations. Permutation tests $(N=10,000)$ on pairwise comparisons using Procrustes distance (Rohlf 1999) were performed to determine which populations differed from one another. Thus a matrix of pairwise Procrustes distances was obtained for each skeletal unit. To allow interpretation of shape variation among populations, TPS deformations grids representing extreme positive and negative deviations along $\mathrm{CV}$ axis were examined. Secondly, two-block partial least-squares analysis (PLS) was used to test whether and how the shape variations of both skeletal units are related. PLS is a multivariate correlation technique that describes the covariation between two sets of variables (shape variables in the context of our study). For an elaborate explanation on this technique, see e.g. Rohlf and Corti (2000); Bookstein et al. (2003); Zelditch et al. (2004). Briefly, PLS help to find correlated pairs of linear combinations (singular vectors, SVD) between two blocks of shape variables. These linear combinations are constructed to display patterns of covariation between the two blocks, just as PCA extracts patterns of variation across the entire block. The RV coefficient, a multivariate analogue of the squared correlation (Escoufier 1973), was used to measure the association between the two blocks of shape variables. It takes values from 0 (completely uncorrelated data) to 1.0 (perfectly correlated data). Permutation tests $(N=10,000)$ allow statistical assessment of the amount of covariance explained by the paired singular vectors (SVD-axes) and the RV coefficient. Thirdly, to test specific patterns of geographical variation related to the Kuroshio Current, we regressed sizecorrected shape data on longitude and latitude for both skeletal units. Significance of these linear relationships was assessed by permutation tests $(N=10,000)$.

In addition to morphological (i.e. Procrustes distances, $P D$ ) and genetic (i.e. Nei's genetic distances, $D_{A}$ ) distances, approximate linear geographical distances between population pairs were obtained with Google ${ }^{\mathrm{TM}}$ Earth software. Then, we used Mantel tests and Procrustes analyses to estimate the statistical correlation between morphological, genetic and geographical distances. First, we computed the correlation between the matrices and a Mantel test with 20,000 random permutations was used for testing the significance of matrix correlation. Another permutation test based on a Procrustes statistic was used to assess the congruence between genetic, morphological and geographical data sets (PROTEST, Jackson 1995; Peres-Neto and Jackson 2001). Procrustes test or PROTEST compares two ordinations using symmetric Procrustes analysis. It is an alternative to a Mantel test, but uses reduced space (i.e. the first axes of ordination methods) instead of complete dissimilarity matrices (see Peres-Neto and Jackson 2001 for detailed explanations on this procedure). Consequently, in a first step, a non-metric multidimensional scaling (NMDS) was separately perfomed on each dissimilarity matrix. Subsequently, the Procrustean fit was implemented between the first two dimensions obtained in each NMDS analysis, the Procrustes correlations were calculated and permutation tests $(N=20,000)$ were used to assess significance.

All the geometric morphometric procedures, regressions, CVAs, PLS were computed with the program MorphoJ (Available from: http://www.flywings.org.uk/Morpho Jpage.htm). NMDS, Mantel and Procrustes tests were done using the ade4, vegan and MASS packages for R Development Core Team (2011).

\section{Results}

\section{Microsatellite}

All five microsatellite loci were polymorphic and did not link with each other, with 4-15 alleles per locus across eight locations (Table 2). The $H_{O}$ and $H_{E}$ per locus across eight locations ranged from 0.412 to 0.933 and from 0.525 to 0.874 , respectively. Significant departures from HardyWeinberg equilibrium after application of Bonferroni adjustment (Rice 1989) were only found in two loci Pom 25 (NS) and Pom2269 (SK). The pairwise Nei's genetic distance matrix was used to construct a Neighbour-Joining tree (Fig. 3). The tree topology indicated two divergent population groups: one group included NS, TS and SK, and the other included populations of mainland Japan. The pairwise $F s t$ values (Table 3) did not significantly differ $(P>0.05)$ among populations from mainland Japan $(\mathrm{KN}$, FS, BS, TN and OS), except pairwise $F s t$ between TN and NS. Moreover, no significant difference was found between TS and SK populations or between SK and NS populations. However, Fst values between populations from mainland Japan and TS and SK were high with significant differentiation $(P<0.05)$. Moreover, the estimated gene flow per generation $(\mathrm{Nm})$ ranged from infinite to 4.136 . The infinite $\mathrm{Nm}$ value indicates that extremely high gene flow has occurred between populations, while those lower than 18 are considered to be restricted gene flow between localities (Table 3) (Wright 1951). In addition, although the nonsignificant $F s t$ was found between BS and NS, the $\mathrm{Nm}$ indicated relative lower genetic exchange $(\mathrm{Nm}=17.233)$.

\section{Morphometrics}

The five populations considered here differed significantly in their mean shapes for both skeletal units (MANOVA; 
Table 2 Comparisons of microsatellite data for the number of alleles $(A)$, sample sizes $(N)$, observed $\left(H_{O}\right)$ and expect $\left(H_{E}\right)$ heterozygosity among individuals of P. coelestis collected from 8 localities
Locality abbreviations are given in Table 1

Values in bold indicate significant heterozygosity deficiency $(P<0.05)$

\begin{tabular}{|c|c|c|c|c|c|c|c|c|}
\hline \multirow[t]{2}{*}{ Locus } & \multicolumn{8}{|c|}{ Populations } \\
\hline & $\mathrm{KN}$ & OS & FS & BS & $\mathrm{TN}$ & NS & SK & $\mathrm{TS}$ \\
\hline \multicolumn{9}{|l|}{ Pom3 } \\
\hline$N$ & 21 & 29 & 15 & 23 & 30 & 22 & 17 & 20 \\
\hline A & 10 & 12 & 7 & 11 & 13 & 10 & 10 & 8 \\
\hline$H_{O}$ & 0.476 & 0.759 & 0.667 & 0.609 & 0.600 & 0.591 & 0.706 & 0.750 \\
\hline$H_{E}$ & 0.610 & 0.748 & 0.738 & 0.622 & 0.779 & 0.737 & 0.788 & 0.778 \\
\hline \multicolumn{9}{|c|}{ Pom25 } \\
\hline$N$ & 21 & 29 & 15 & 23 & 30 & 22 & 17 & 20 \\
\hline$A$ & 13 & 14 & 10 & 13 & 13 & 12 & 15 & 14 \\
\hline$H_{O}$ & 0.762 & 0.862 & 0.800 & 0.739 & 0.767 & 0.591 & 0.882 & 0.950 \\
\hline$H_{E}$ & 0.872 & 0.860 & 0.729 & 0.874 & 0.820 & 0.735 & 0.882 & 0.859 \\
\hline \multicolumn{9}{|c|}{ AC1578 } \\
\hline$N$ & 21 & 29 & 15 & 23 & 30 & 22 & 17 & 20 \\
\hline A & 8 & 8 & 5 & 7 & 7 & 5 & 5 & 7 \\
\hline$H_{O}$ & 0.667 & 0.897 & 0.800 & 0.826 & 0.700 & 0.818 & 0.706 & 0.650 \\
\hline$H_{E}$ & 0.798 & 0.795 & 0.749 & 0.729 & 0.749 & 0.672 & 0.686 & 0.685 \\
\hline \multicolumn{9}{|c|}{ Pom2416 } \\
\hline$N$ & 21 & 29 & 15 & 23 & 30 & 22 & 17 & 20 \\
\hline$A$ & 7 & 6 & 7 & 6 & 7 & 5 & 6 & 4 \\
\hline$H_{O}$ & 0.857 & 0.793 & 0.933 & 0.783 & 0.733 & $0.5^{*}$ & 0.588 & 0.550 \\
\hline$H_{E}$ & 0.785 & 0.671 & 0.793 & 0.725 & 0.758 & 0.617 & 0.638 & 0.491 \\
\hline \multicolumn{9}{|c|}{ Pom 2269} \\
\hline$N$ & 21 & 29 & 15 & 23 & 30 & 22 & 17 & 20 \\
\hline A & 10 & 6 & 8 & 8 & 9 & 6 & 6 & 5 \\
\hline$H_{O}$ & 0.810 & 0.586 & 0.533 & 0.652 & 0.633 & 0.455 & 0.412 & 0.550 \\
\hline$H_{E}$ & 0.729 & 0.525 & 0.749 & 0.651 & 0.603 & 0.573 & 0.652 & 0.588 \\
\hline
\end{tabular}
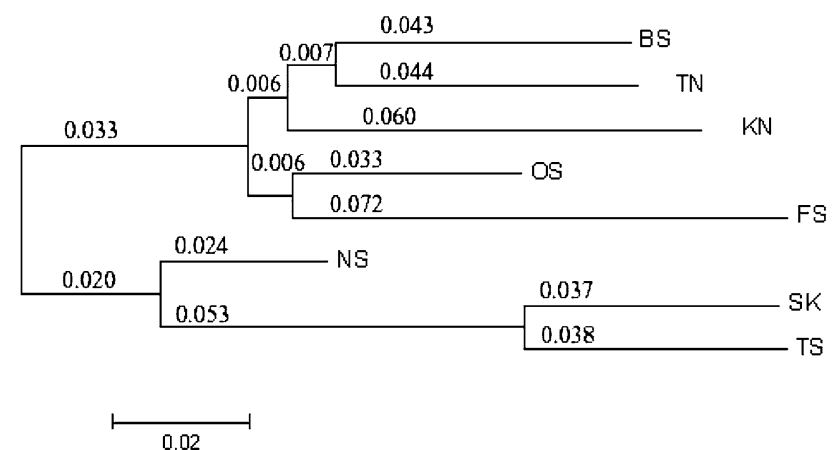

Fig. 3 Neighbour-joining tree showing the genetic relationships between the eight sampled populations of $P$. coelestis based on $D_{A}$ distances for genotyping data. Numbers above lines indicate branch lengths. Locality abbreviations are given in Table 1

mandible: $\lambda_{W I L K S}=0.0308, F=3.141, d f=104,232.6$, $P<0.001$; premaxilla: $\lambda_{\text {WILKS }}=0.2399, \quad F=2.719$, $d f=48,290.9, P<0.001)$. Pairwise comparisons based on Procrustes Distance show significant differences among the five populations for the mandible $(P<0.05$ in every case, Table 4). The highest and the lowest Procrustes Distances were found between BS and TS, and KN and OS, respectively. Conversely, some populations did not show differences for the shape of the premaxilla (Table 4). Indeed non-significant difference was found between TS and BS, TS and SK, and SK and OS. The highest Procrustes Distance was found between BS and OS.

The ordinations of populations by canonical variate analysis corroborate the findings that shape differences are significant among populations although some overlaps are present in the scatters of data (Figs. 4a, 5a). The morphological interpretation of the canonical axes indicates a major contribution of localized shape differences in the oral jaws. For the mandible, CV1 and CV2 explain together $75 \%$ of the total variation in the dataset (Fig. 4a). CV1 allowed the clear distinction of both populations of the south, i.e. SK and TS, from the others. Specimens of SK and TS show a more lengthened ventral region of the retroarticular (LMs 7-8) and a less high dentary (LMs 2 and 13) than the others (Fig. 4b). If the individuals of $\mathrm{KN}$ occupy a relatively central place in the shape space defined by CV1 and CV2, specimens of BS have the highest values along CV2 and specimens of OS have the lowest. Pomacentrus coelestis of the BS region show (1) lower coronoid 
Table 3 Pairwise comparisons among 8 populations of $P$. coelestis using molecular data

\begin{tabular}{lllllrrrr}
\hline & KN & OS & FS & BS & TN & NS & SK \\
\hline KN & - & 40.734 & 118.798 & $\infty$ & 29.162 & 10.081 & 10.210 \\
OS & 0.006 & & 28.159 & 69.194 & 156.000 & 11.598 & 17.736 \\
FS & 0.002 & 0.009 & & 67.318 & 25.523 & 33.534 & 10.434 & 5.586 \\
BS & -0.007 & 0.004 & 0.004 & & 49.750 & 17.233 & 14.720 & 7.039 \\
TN & 0.009 & 0.002 & 0.010 & 0.005 & & 6.000 & 8.711 \\
NS & 0.024 & 0.021 & 0.007 & 0.014 & $\mathbf{0 . 0 4 0}$ & & 4.136 \\
SK & $\mathbf{0 . 0 2 4}$ & $\mathbf{0 . 0 1 4}$ & $\mathbf{0 . 0 2 3}$ & $\mathbf{0 . 0 1 7}$ & $\mathbf{0 . 0 2 8}$ & 0.006 & 77.417 \\
TS & $\mathbf{0 . 0 5 2}$ & $\mathbf{0 . 0 3 7}$ & $\mathbf{0 . 0 4 4}$ & $\mathbf{0 . 0 3 4}$ & $\mathbf{0 . 0 5 7}$ & 0.003 & -0.005 \\
\hline Pair & & & & & $\infty$ \\
\hline
\end{tabular}

Pairwise $F_{S T}$ values for multi-locus nuclear data are below diagonal and $\mathrm{Nm}$ values are shown above diagonal. Locality abbreviations are given in Table 1

Indicative adjusted nominal level (5\%) for multiple comparisons is 0.001786 . Values in bold indicate significant differences $(P<0.05)$

Table 4 Pairwise comparisons among 5 populations of $P$. coelestis using shape data

\begin{tabular}{llllll}
\hline & KN & OS & BS & SK & TS \\
\hline Mandible & & & & & \\
KN & & $\mathbf{0 . 0 3 8 1}$ & $\mathbf{0 . 0 0 5 6}$ & $\mathbf{0 . 0 0 2 8}$ & $\mathbf{0 . 0 1 6 9}$ \\
OS & 0.0202 & & $\mathbf{0 . 0 0 0 1}$ & $\mathbf{< . 0 0 0 1}$ & $\mathbf{0 . 0 0 5 7}$ \\
BS & 0.0239 & 0.0318 & & $\mathbf{0 . 0 0 1 9}$ & $<\mathbf{0 . 0 0 0 1}$ \\
SK & 0.0244 & 0.0328 & 0.0269 & & $\mathbf{0 . 0 1 8 6}$ \\
TS & 0.0229 & 0.0254 & 0.0340 & 0.0226 & \\
Premaxilla & & & & & \\
KN & & $\mathbf{0 . 0 1 5 7}$ & $<\mathbf{0 . 0 0 0 1}$ & $\mathbf{0 . 0 0 2 1}$ & $\mathbf{0 . 0 0 8 2}$ \\
OS & 0.0200 & & $<\mathbf{0 . 0 0 0 1}$ & 0.0808 & $\mathbf{0 . 0 0 3 0}$ \\
BS & 0.0286 & 0.0323 & & $\mathbf{0 . 0 0 1 0}$ & 0.3683 \\
SK & 0.0241 & 0.0178 & 0.0232 & & 0.0588 \\
TS & 0.0206 & 0.0246 & 0.0115 & 0.0176 & \\
\hline
\end{tabular}

Fig. 4 a CVA ordination for the five populations of $P$. coelestis from mandible analysis, b Deformation grids and vectors displacement along the first two CV axes, depicting shape variation from the lowest to highest values. The shape variations along $\mathrm{CV}$ axes have been exaggerated for better visualization $(\times 10)$. Localities are indicated by different symbols and the abbreviations are given in Table 1 (a)

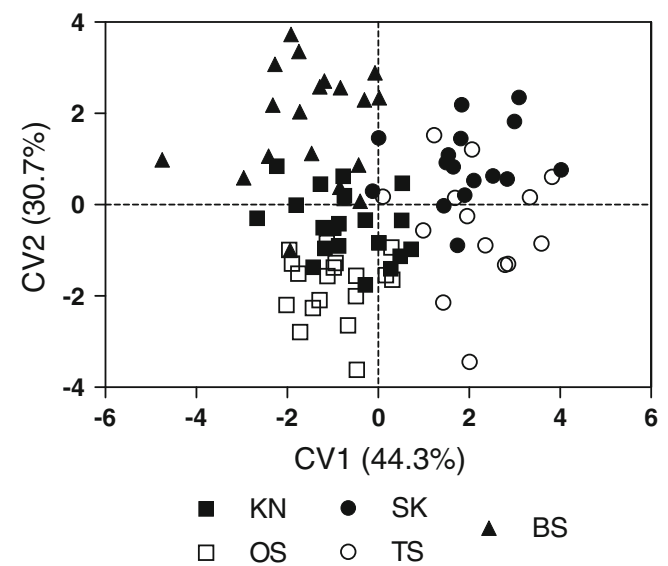

(b)

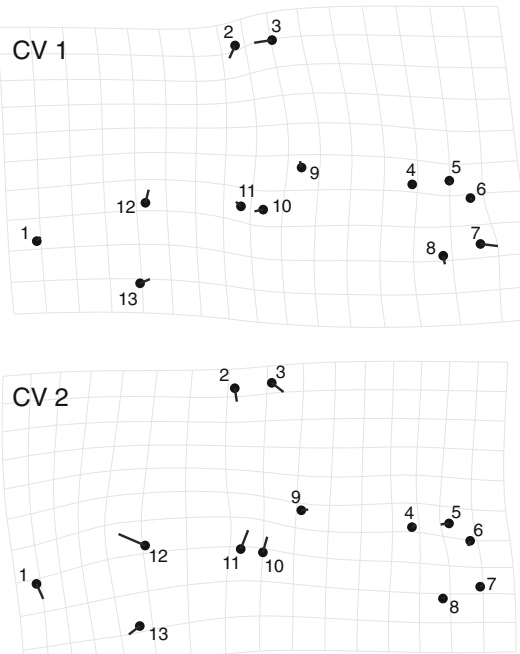

processes of the dentary and of the articulo-angular (LMs 2 and 3), (2) a longer anterior region of the articulo-angular penetrating far in the dentary (LMs 10-12) and (3) a shorter symphysis mandibulae (LMs 1 and 13) in comparison with the populations of $\mathrm{KN}$ and OS (Fig. 4b). Concerning the premaxilla (Fig. 5), the CV1 and the CV2 
Fig. 5 a CVA ordination for the five populations of $P$. coelestis from premaxilla analysis, b Deformation grids and vectors displacement along the first two CV axes, depicting shape variation from the lowest to highest values. The shape variations along $\mathrm{CV}$ axes have been exaggerated for better visualization $(\times 10)$. Localities are indicated by different symbols and the abbreviations are given in Table 1 (a)

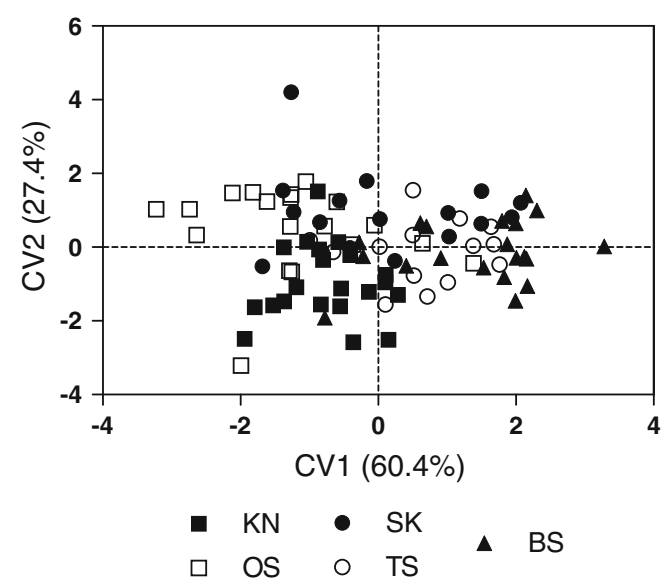

(b) CV 1

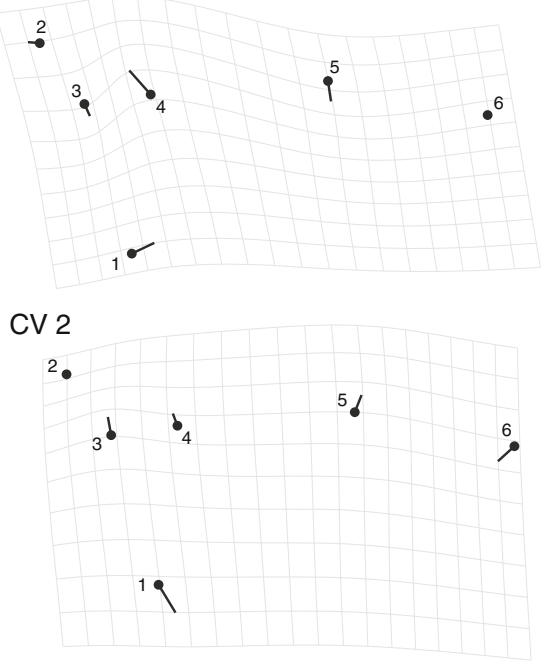

respectively account for about 60.4 and $27.4 \%$ of the total shape variation. In this shape space, $P$. coelestis of the northern populations (i.e. OS and $\mathrm{KN}$ ) have the lowest values on CV1 associated to a longer dentigerous process (LMs 1 and 6) and a shorter maxillad spine of the premaxilla (LM 4) in comparison with the other populations (Fig. 5b). CV2 mainly explains variation of the length of the ascending process of the premaxilla (LMs 1 and 2) observed in every population (Fig. 5b).

PLS analysis revealed that the shape variation of both skeletal mouthparts is totally unrrelated ( $R V$ coefficient $=0.1129 ; P=0.134)$.

Although significant linear relationships exist between shape and geographical data, latitude and longitude explain a low level of shape variance for both skeletal units (from 2.6 to $4.4 \%$ of total shape variation, Table 5). However, the regressions along the latitudes give a model with a higher percentage of explained shape variance for each skeletal unit.

For the mandible and the premaxilla, Mantel and Procrustes tests revealed no significant relationship between morphological and genetic differentiation $(P>0.05$,

Table 5 Results of linear regressions between shape data and geographical variables (longitude and latitude)

\begin{tabular}{llc}
\hline & Explained variance (\%) & $P$-values \\
\hline $\begin{array}{l}\text { Mandible } \\
\text { Shape versus longitude }\end{array}$ & 2.652 & \\
Shape versus latitude & 3.8133 & 0.0156 \\
Premaxilla & & 0.0011 \\
Shape versus longitude & 2.8186 & \\
Shape versus latitude & 4.4176 & 0.0191 \\
\hline
\end{tabular}

Significance of the relationships are obtained by permutation tests $(N=10,000)$. Shape refers to "size corrected-shape data"
Table 6 Results of Mantel and Procrustes tests

\begin{tabular}{|c|c|c|c|c|}
\hline & \multicolumn{2}{|c|}{ Mantel test } & \multicolumn{2}{|c|}{ Procrustes test } \\
\hline & $r$ & $\begin{array}{l}P \text { - } \\
\text { values }\end{array}$ & $r$ & $\begin{array}{l}P \text { - } \\
\text { values }\end{array}$ \\
\hline Mandible versus genetic & 0.3037 & 0.1905 & 0.6902 & 0.2483 \\
\hline Premaxilla versus genetic & -0.3105 & 0.8141 & 0.5284 & 0.5172 \\
\hline Mandible versus geography & -0.2524 & 0.7010 & 0.7460 & 0.1869 \\
\hline $\begin{array}{l}\text { Premaxilla versus } \\
\text { geography }\end{array}$ & -0.3240 & 0.8503 & 0.5954 & 0.4756 \\
\hline
\end{tabular}

Significance of the relationships is obtained by permutation tests $(N=20,000)$

Table 6). The congruence between the morphological and geographical data (i.e. linear distances) sets is also not statistically significant $(P>0.05$ for Mantel and Procrustes tests, Table 6).

\section{Discussion}

Sampled populations of $P$. coelestis differ in both genetic and morphological traits, but these character sets appear to be unrelated with each other, as well as with geographical distances (Table 6). The observed morphological variations found among populations are not totally related to population structure highlighted by microsatellites. Our results could be explained by evolutionary forces acting on loci responsible for morphological differences or by phenotypic plasticity under environmental factors.

\section{Morphological Variations}

We found significant morphological differentiation among populations of $P$. coelestis. Overall, the patterns of 
morphological changes assessed from the shape of the mandible and the premaxilla are not congruent. The morphometric analyses of the mandible highlight significant morphological divergence among all studied populations. On the other hand, some populations do not differ in premaxillary shapes (Table 4). In this case, it appears that the shape of the mandible is more divergent than the shape of the premaxilla. Several explanations could be responsible for this incongruence. Firstly, it could be due to incomplete assessment of the information about the shape of premaxilla. A reduced power to detect variation in the premaxilla is likely, knowing that less than half the number of LMs (in comparison with the mandible) was used to assess shape comparison. Moreover, the three-dimensional assessment of the shape could be more relevant than the two-dimensional projection. Secondly, it could be due to different functional demands of each skeletal unit. The "L-like" shape of the premaxilla offers only two main axes of shape variation: the length of the dentigerous process and the length of the ascending process, which are directly linked to the protrusion efficiency during suction-feeding (Barel 1983; Otten 1983; Liem 1993). It is well known that the lower jaw of all Perciforms can be depressed through various mechanisms (Osse 1969; Liem and Osse 1975; Elshoud-Oldenhave and Osse 1976; Liem 1978). In damselfishes and other Perciforms, two muscles (i.e. adductor mandibulae and geniohyohydeus), ligaments and tendons are connected to the mandible allowing its elevation and depression (Osse 1969; Liem and Osse 1975; Liem 1978). Conversely, no muscle is directly attached to the premaxilla. These anatomical differences could explain variable amount of stress on each skeletal unit during mouth opening and closing, and could ultimately lead to various sources of skeletal shape variation. Third, the number of elements composing the structure may play an important role explaining this incongruence. Indeed, the mandible is made of two dermal bones (i.e. dentary and retroarticular) and one endochondral bone (i.e. articular) having clear different developmental origins. The premaxilla is a unique dermal bone. These modular characteristics of the mandible could explain a higher shape variation among populations than in premaxilla (Klingenberg 2008, 2009). Fourthly, the number of genetic factors underlying morphological differences could explain the difference in the amount of shape variation between the premaxilla and the mandible. Albertson et al. (2003) estimated that shape variation in the premaxilla and the mandible is controlled by 7.7 and 10.5 factors in cichlid fishes, respectively. This difference should be similar in damselfishes, knowing that they are closely phylogeneticaly related to cichlids (Nelson 2006; Mabuchi et al. 2007). We cannot conclude which explanation is the most likely but it could be expected that the incongruence between mandible and premaxilla shape variation results from combined effects.
It is well known that the shape of oral jaws as well as their teeth are highly related to the diet and the way of feeding in fishes (Liem 1993; Wainwright and Richard 1995). Although $P$. coelestis feeds mainly on planktonic copepods (Kuo and Shao 1991), the shape divergence observed among populations could be explained by diet variation. Previous ecomorphological studies in damselfishes (Gluckmann and Vandewalle 1998; Frédérich et al. 2008; Frédérich and Vandewalle 2011) allow interpretations of shape variation of both studied structural units. For example, thinner and proportionally longer mandibles observed in $P$. coelestis populations from TS, SK and OS could suggest a higher level of planktivory than in the two others. Conversely, more robust mandibles observed in BS and $\mathrm{KN}$ populations may suggest higher levels of grazing and/or biting activities. The premaxilla showed low levels of shape variation among populations although a longer maxillad spine of the premaxilla in P. coelestis from TS and SK strengthens our statement about a higher level of planktivory in these populations. Indeed, long ascending process and long maxillad spine of the premaxilla are generally linked to high levels of jaw protrusion in acanthopterygian fishes and positively related to ram-suction feeding efficiency (Otten 1983). However, the study of other morphological data and a rigorous study of the diet (Frédérich et al. 2009) should strengthen our hypothesis made on mandible and premaxilla shape variation.

\section{Population Structure: Morphological Versus Genetic Markers}

Our morphological and genetic data strengthen previous results on the population structure of $P$. coelestis in northwestern Pacific Ocean (Liu et al. 2008). A genetic break was found between populations from mainland Japan and Okinawa-Taiwan and this break is congruent with some patterns of morphological variation. Indeed, the main axis of mandible shape variation (CV1, Fig. 4) directly opposed the populations of Sesoko Is. and Tawain to the populations of mainland Japan.

On the other hand, Mantel and Procrustes tests revealed discordance between the morphological and genetic structures (Table 6). This discordance can be explained by various factors: elevated molecular lineage diversification, phenotypic plasticity or rapid morphological divergence under environmental factors. The present study shows that some morphological traits, such as the shape of oral jaws, vary more rapidly than genetic characters, such as microsattelites, in the coral reef damselfish $P$. coelestis. Geometric morphometric methods are known as a highly powerful tool for detecting shape variation, even very small ones (Adams et al. 2004; Zelditch et al. 2004). Shape differences among $P$. coelestis populations are obvious, especially for the 
mandible (Table 4) but the magnitude of variation is lower than those of inter-specific comparisons (Frédérich et al. 2008). Latitude and longitude explain a very low level of shape variance among $P$. coelestis populations (Table 5); and Mantel and Procrustes tests revealed no correlation between geographical distances and morphological divergences (Table 6). Consequently shape variations among populations should be induced in a rather complex manner, i.e. related to multiple ecological and genetic factors.

The no-congruence between morphological and genetic data could be explained by phenotypic plasticity. Indeed, the phenotypic plasticity of feeding structures (i.e. oral and pharyngeal jaws and their associated teeth) has already been highlighted in various freshwater fishes (Hegrenes 2001; Streelman et al. 2007; Muschick et al. 2011). Bouton et al. (2002) experimentally tested different food regimes in a cichlid species and demonstrated that even small differences in diet naturally induced morphological variations. The different regimes tested by Bouton et al. (2002), i.e. filamentous algae versus zooplankton versus "algae + zooplankton", reflects to the main axis of trophic diversity in damselfishes (Cooper and Westneat 2009; Frédérich et al. 2009). Consequently, the same kind of diet differences in $P$. coelestis populations could induce shape variation of the oral jaws. Then it is intriguing to speculate that morphological variation between $P$. coelestis populations reflects differences in resource abundance and/or community structure among local habitats. Such skeletal shape variations in coral reef fishes were relatively unexpected assuming that environmental factors of coral reefs do not vary at this relatively small spatial scale (geographical distances $<1,000 \mathrm{~km}$ between the closest studied regions) but our results suggest the potential phenotypic plasticity of feeding structures in coral reef fishes.

Kokita $(2003,2004)$ highlighted latitudinal variations of reproductive traits of $P$. coelestis populations in the same regions (i.e. Ryukyu Islands and mainland Japan). He showed that their clutch size and size-specific clutch weight increased with increasing latitude. In the present study, latitude explained a low level of morphological shape variation (Table 5). It could be assumed that the level of plasticity of reproductive traits varies from that of morphological traits. The genetic break between the populations of mainland Japan and Okinawa-Taiwan suggests that the latitudinal variation of reproductive traits among $P$. coelestis populations is likely genetically based (see discussion in Liu et al. 2008). The present study did not find a congruent pattern between genetic and morphological structure, suggesting the morphological variation of jaw may be caused by phenotypic plasticity and/or local adaptation. Our genetic data are based on five neutral microsattelite loci, which is informative from a biogeographical standpoint. However, it is not sufficient to discriminate between plasticity and adaptive divergence, especially if the adaptive trait has a relatively simple genetic basis. Recently, Roberts et al. (2011) highlighted that a variation in the length of the retroarticular process is controlled by a discrete genetic factor regulating the expression of the hedgehog receptor, Ptch 1 , in cichlids. It was suggested that Ptch 1 polymorphism may contribute to ecological speciation and morphological differentiation in lake Malawi cichlid fish (Roberts et al. 2011). In a similar way, the lengthened retroarticular process observed in SK and TS populations of $P$. coelestis (Fig. 4) could be associated to a same kind of genomic polymorphism. Consequently, caution should be taken while interpreting the lack of concordance between morphological and genetic data. The study of genetic variation in other morphogenetic genes such as Bmp4 or CaM1 (Albertson et al. 2005; Parsons and Albertson 2009) or genome-scale sequence comparison (Loh et al. 2008) among populations may provide valuable information about the genetic signal underlying shape variation of oral jaws in the future.

\section{Conclusions}

Shape analysis of the mandible and the premaxilla revealed morphological variations among $P$. coelestis populations in the northwestern Pacific Ocean. No congruence exists between morphological and genetic structures in these populations. The studied morphological traits appear more variable than genetic ones in $P$. coelestis. Almost all studied populations show differences in shape when genetic variations are mainly present between populations of mainland Japan and Okinawa-Taiwan. This study highlights an unexpected level of shape variation among populations living in a relatively stable environment like coral reefs. Good candidates of evolutionary mechanisms underlying these shape variations are phenotypic plasticity and adaptive divergence among populations. Plasticity, adaptation, or both should be involved in these morphological differences of $P$. coelestis populations.

Acknowledgments We would like to thank Dr. Kokita, Ming-Jay Ho and Dr. Yu-Rong Cheng for fish sampling. We thank two anonymous reviewers for valuable comments on this manuscript. This study was partially supported by a grant (NSC95-2611-M002-011MY3) from the National Science Council, ROC to CFD. Bruno Frédérich is a Postdoctoral Researcher of the F.R.S.-FNRS (Belgium).

\section{References}

Adams, D. C., Rohlf, F. J., \& Slice, D. E. (2004). Geometric morphometrics: Ten years of progress following the 'revolution'. Italian Journal of Zoology, 71(1), 5-16.

Albertson, R. C., Streelman, J. T., \& Kocher, T. D. (2003). Genetic basis of adaptive shape differences in the cichlid head. Journal of Heredity, 94(4), 291-301. 
Albertson, R. C., Streelman, J. T., Kocher, T. D., \& Yelick, P. C. (2005). Integration and evolution of the cichlid mandible: The molecular basis of alternate feeding strategies. Proceedings of the National Academy of Sciences of the United States of America, 102(45), 16287-16292.

Alibert, P., Moureau, B., Dommergues, J. L., \& David, B. (2001). Differentiation at a microgeographical scale within two species of ground beetle, Carabus auronitens and C-nemoralis (Coleoptera, Carabidae): A geometrical morphometric approach. Zoologica Scripta, 30(4), 299-311.

Allen, G. R. (Ed.). (1991). Damselfishes of the world (p. 271). Melle: Publication of Natural History and Pets Book, Mergus.

Barel, C. D. N. (1983). Towards a constructional morphology of cichlid fishes (Teleostei, Perciformes). Netherlands Journal of Zoology, 33(4), 357-424.

Bell, L. J., Moyer, J. T., \& Numachi, K. (1982). Morphological and genetic variation in Japanese populations of the anemonefish Amphiprion clarkii. Marine Biology, 72, 99-108.

Bernardi, G., Holbrook, S. J., Schmitt, R. J., Crane, N. L., \& DeMartini, E. (2002). Species boundaries, populations and colour morphs in the coral reef three-spot damselfish (Dascyllus trimaculatus) species complex. Proceedings of the Royal Society of London Series B-Biological Sciences, 269(1491), 599-605.

Bookstein, F. (1991). Morphometric tools for landmark data: Geometry and biology. Cambridge: University Press.

Bookstein, F. L., Gunz, P., Mitteroecker, P., Prossinger, H., Schaefer, K., \& Seidler, H. (2003). Cranial integration in Homo: Singular warps analysis of the midsagittal plane in ontogeny and evolution. Journal of Human Evolution, 44(2), 167-187.

Bouton, N., Witte, F., \& Van Alphen, J. J. M. (2002). Experimental evidence for adaptive phenotypic plasticity in a rock-dwelling cichlid fish from Lake Victoria. Biological Journal of the Linnean Society, 77(2), 185-192.

Bowen, B. W., Muss, A., Rocha, L. A., \& Grant, W. S. (2006). Shallow mtDNA coalescence in atlantic pygmy angelfishes (Genus Centropyge) indicates a recent invasion from the Indian Ocean. Journal of Heredity, 97(1), 1-12.

Bunje, P. M. E. (2005). Pan-European phylogeography of the aquatic snail Theodoxus fluviatilis (Gastropoda : Neritidae). Molecular Ecology, 14(14), 4323-4340.

Cardini, A., Jansson, A.-U., \& Elton, S. (2007). A geometric morphometric approach to the study of ecogeographical and clinal variation in vervet monkeys. Journal of Biogeography, 34(10), 1663-1678.

Cooper, W. J., \& Westneat, M. W. (2009). Form and function of damselfish skulls: rapid and repeated evolution into a limited number of trophic niches. BMC Evolutionary Biology, 9, 24.

Dieringer, D., \& Schlotterer, C. (2003). MICROSATELLITE ANALYSER (MSA): A platform independent analysis tool for large microsatellite data sets. Molecular Ecology Notes, 3(1), 167-169.

Drew, J. A., Allen, G. R., \& Erdmann, M. V. (2010). Congruence between mitochondrial genes and color morphs in a coral reef fish: Population variability in the Indo-Pacific damselfish Chrysiptera rex (Snyder, 1909). Coral Reefs, 29(2), 439-444.

Edwards, S., Claude, J., Van Vuuren, B. J., \& Matthee, C. A. (2011). Evolutionary history of the Karoo bush rat, Myotomys unisulcatus (Rodentia: Muridae): Disconcordance between morphology and genetics. Biological Journal of the Linnean Society, 102(3), $510-526$.

Elshoud-Oldenhave, M. J. W., \& Osse, J. W. M. (1976). Functional morphology of the feeding system in the ruff-Gymnocephalus cernua (L. 1758)-(Teleostei, Percidae). Journal of Morphology, 150(2), 399-422.

Escoufier, Y. (1973). Le traitement des variables vectorielles. Biometrics, 29, 751-760.
Excoffier, L., Laval, G., \& Schneider, S. (2005). Arlequin (version 3.0): An integrated software package for population genetics data analysis. Evolutionary Bioinformatics, 1, 47-50.

Frédérich, B., Fabri, G., Lepoint, G., Vandewalle, P., \& Parmentier, E. (2009). Trophic niches of thirteen damselfishes (Pomacentridae) at the Grand Récif of Toliara, Madagascar. Ichthyological Research, 56(1), 10-17.

Frédérich, B., Pilet, A., Parmentier, E., \& Vandewalle, P. (2008). Comparative trophic morphology in eight species of damselfishes (Pomacentridae). Journal of Morphology, 269(2), 175-188.

Frédérich, B., \& Sheets, H. D. (2010). Evolution of ontogenetic allometry shaping giant species: A case study from the damselfish genus Dascyllus (Pomacentridae). Biological Journal of the Linnean Society, 99(1), 99-117.

Frédérich, B., \& Vandewalle, P. (2011). Bipartite life cycle of coral reef fishes promotes increasing shape disparity of the head skeleton during ontogeny: An example from damselfishes (Pomacentridae). BMC Evolutionary Biology, 11, 82.

Garnier, S., Magniez-Jannin, F., Rasplus, J. Y., \& Alibert, P. (2005). When morphometry meets genetics: Inferring the phylogeography of Carabus solieri using Fourier analyses of pronotum and male genitalia. Journal of Evolutionary Biology, 18(2), 269-280.

Gluckmann, I., \& Vandewalle, P. (1998). Morphofunctional analysis of the feeding apparatus in four Pomacentridae species: Dascyllus aruanus, Chromis retrofasciata, Chrysiptera biocellata and C-unimaculata. Italian Journal of Zoology, 65, 421-424.

Goudet, J. (1995). FSTAT (Version 1.2): A computer program to calculate F-statistics. Journal of Heredity, 86(6), 485-486.

Guo, S. W., \& Thompson, E. A. (1992). Performing the exact test of Hardy-Weinberg proportion for multiple alleles. Biometrics, 48(2), 361-372.

Hegrenes, S. (2001). Diet-induced phenotypic plasticity of feeding morphology in the orangespotted sunfish, Lepomis humilis. Ecology of Freshwater Fish, 10(1), 35-42.

Jackson, D. A. (1995). PROTEST - A Procrustean randomization test of community environment concordance. Ecoscience, 2(3), 297-303.

Jones, G. P., Milicich, M. J., Emslie, M. J., \& Lunow, C. (1999). Selfrecruitment in a coral reef fish population. Nature, 402(6763), 802-804

Jones, G. P., Planes, S., \& Thorrold, S. R. (2005). Coral reef fish larvae settle close to home. Current Biology, 15(14), 1314-1318.

Klingenberg, C. P. (1998). Heterochrony and allometry: The analysis of evolutionary change in ontogeny. Biological Reviews, 73(1), $79-123$.

Klingenberg, C. P. (2008). Morphological integration and developmental modularity. Annual Review of Ecology, Evolution, and Systematics, 39, 115-132.

Klingenberg, C. P. (2009). Morphometric integration and modularity in configurations of landmarks: Tools for evaluating a priori hypotheses. Evolution \& Development, 11(4), 405-421.

Kokita, T. (2003). Potential latitudinal variation in egg size and number of a geographically widespread reef fish, revealed by common-environment experiments. Marine Biology, 143(3), 593-601.

Kokita, T. (2004). Latitudinal compensation in female reproductive rate of a geographically widespread reef fish. Environmental Biology of Fishes, 71(3), 213-224.

Kuo, S.-R., \& Shao, K.-T. (1991). Feeding habits of damselfishes (Pomacentridae) from the southern part of Taiwan. Journal of the Fisheries Society of Taiwan, 18(3), 165-176.

Leis, J. M. (1991). The pelagic stage of reef fishes. In P. F. Sale (Ed.), The ecology of fishes on coral reefs (pp. 183-230). San Diego: Academic Press.

Liem, K. F. (1978). Modulatory multiplicity in the functional repertoire of the feeding mechanism in cichlid fishes. Journal of Morphology, 158(3), 323-360. 
Liem, K. F. (1993). Ecomorphology of the teleostean skull. In J. Hanken \& B. K. Hall (Eds.), The skull: functional and evolutionary mechanisms (pp. 422-452). Chicago: The University of Chicago Press.

Liem, K. F., \& Osse, J. W. M. (1975). Biological versatility, evolution, and food resource exploitation in african cichlid fishes. American Zoologist, 15, 427-454.

Liu, S., Dai, C. F., Fan, T. Y., \& Yu, H. T. (2005). Cloning and characterization of Microsatellite loci in a gorgonian coral, Junceella juncea (Anthozoa; Octocorallia; Ellisellidae) and its application in clonal genotyping. Marine Biotechnology, 7(1), 26-32.

Liu, S.-Y. V., Kokita, T., \& Dai, C.-F. (2008). Population genetic structure of the neon damselfish (Pomacentrus coelestis) in the northwestern Pacific Ocean. Marine Biology, 154(4), 745-753.

Liu, S.-Y. V., Yu, H.-T., \& Dai, C.-F. (2007). Eight microsatellite loci in Clark's anemonefish, Amphiprion clarkii. Molecular Ecology Notes, 7(6), 1169-1171.

Loh, Y.-H. E., Katz, L. S., Mims, M. C., Kocher, T. D., Yi, S. V., \& Streelman, J. T. (2008). Comparative analysis reveals signatures of differentiation amid genomic polymorphism in Lake Malawi cichlids. Genome Biology, 9(7), R113.

Mabuchi, K., Miya, M., Azuma, Y., \& Nishida, M. (2007). Independent evolution of the specialized pharyngeal jaw apparatus in cichlid and labrid fishes. BMC Evolutionary Biology, 7, 10.

McMillan, W. O., Weigt, L. A., \& Palumbi, S. R. (1999). Color pattern evolution, assortative mating, and genetic differentiation in brightly colored butterflyfishes (Chaetodontidae). Evolution, 53(1), 247-260.

Michaux, J. R., Magnanou, E., Paradis, E., Nieberding, C., \& Libois, R. (2003). Mitochondrial phylogeography of the Woodmouse (Apodemus sylvaticus) in the Western Palearctic region. Molecular Ecology, 12(3), 685-697.

Miller-Sims, V., Delaney, M., Atema, J., Kingsford, M. J., \& Gerlach, G. (2005). DNA microsatellites in the neon damselfish (Pomacentrus coelestis). Molecular Ecology Notes, 5(2), 424-426.

Molina, W. F., Shibatta, O. A., \& Galetti-Jr, P. M. (2006). Multivariate morphological analysis in continental and island populations of Abudefduf saxatilis (Linnaeus) (Pomacentridae, Perciformes) of Wesern Atlantic. Pan-American Journal of Aquatic Sciences, 1(2), 49-56.

Muschick, M., Barluenga, M., Salzburger, W., \& Meyer, A. (2011). Adaptive phenotypic plasticity in the Midas cichlid fish pharyngeal jaw and its relevance in adaptive radiation. BMC Evolutionary Biology, 11, 116.

Nei, M., Tajima, M., \& Tateno, Y. (1983). Accuracy of estimated phylogenetic trees from molecular data. Journal of Molecular Evolution, 19, 153-170.

Nelson, J. S. (2006). Fishes of the world (p. 601). Hoboken: Wiley.

Nice, C. C., \& Shapiro, A. M. (1999). Molecular and morphological divergence in the butterfly genus Lycaeides (Lepidoptera: Lycaenidae) in North America: Evidence of recent speciation. Journal of Evolutionary Biology, 12(5), 936-950.

Osse, J. W. M. (1969). Functional morphology of the head of the perch (Perca fluvatilis L.): An electromyographic study. Netherlands Journal of Zoology, 19(3), 289-392.

Otten, E. (1983). The jaw mechanism during growth of a genralized Haplochromis species: H. elegans Trewavas 1933 (Pisces, Cichlidae). Netherlands Journal of Zoology, 33(1), 55-98.

Parsons, K. J., \& Albertson, R. C. (2009). Roles for Bmp4 and CaM1 in shaping the jaw: Evo-devo and beyond. Annual Review of Genetics, 43, 369-388.

Peres-Neto, P. R., \& Jackson, D. A. (2001). How well do multivariate data sets match? The advantages of a Procrustean superimposition approach over the Mantel test. Oecologia, 129(2), 169-178.
Planes, S. (1993). Genetic differentiation in relation to restricted larval dispersal of the convict surgeonfish Acanthurus triostegus in French Polynesia. Marine Ecology-Progress Series, 98(3), 237-246.

R Development Core Team. (2011). R: A language and environment for statistical computing. Vienna, Austria: R Foundation for Statistical Computing. ISBN: 3-900051-07-0. http://www.R-project.org/.

Raymond, M., \& Rousset, F. (1995). GENEPOP (Version-1.2)Population-genetics software for exact tests and ecumenicism. Journal of Heredity, 86(3), 248-249.

Rice, W. R. (1989). Analyzing tables of statistical tests. Evolution, 43(1), 223-225.

Roberts, R. B., Hu, Y., Albertson, R. C., \& Kocher, T. D. (2011). Craniofacial divergence and ongoing adaptation via the hedgehog pathway. Proceedings of the National Academy of Sciences of the United States of America, 108(32), 13194-13199.

Rocha, L. A. (2004). Mitochondrial DNA and color pattern variation in three western Atlantic Halichoeres (labridae), with the revalidation of two species. Copeia, 4, 770-782.

Rocha, L. A., Robertson, D. R., Roman, J., \& Bowen, B. W. (2005). Ecological speciation in tropical reef fishes. Proceedings of the Royal Society B-Biological Sciences, 272(1563), 573-579.

Rohlf, F. J. (1993). Relative warps analysis and an example of its application to mosquito wings. In L. F. Marcus, E. Bello, A. G-V, (Eds.), Contributions to morphometrics (pp. 131-159). Madrid: Monografias del Museo Nacional de Ciencias Naturales, CSIC.

Rohlf, F. J. (1999). On the use of shape spaces to compare morphometric methods. Hystrix, 11, 1-17.

Rohlf, F. J., \& Corti, M. (2000). Use of two-block partial leastsquares to study covariation in shape. Systematic Biology, 49(4), 740-753.

Rohlf, F. J., \& Marcus, L. F. (1993). A revolution in morphometrics. Trends in Ecology \& Evolution, 8(4), 129-132.

Rohlf, F. J., \& Slice, D. (1990). Extensions of the Procrustes method for the optimal superimposition of landmarks. Systematic Zoology, 39(1), 40-59.

Sale, P. F. (1980). The ecology of fishes on coral reefs. Oceanography and Marine Biology, 18, 367-421.

Sale, P. F. (1991). Reef fish communities: open nonequilibrial systems. In P. F. Sale (Ed.), The ecology of fishes on coral reefs (pp. 564-598). San Diego, CA: Academic Press.

Schultz, J. K., Pyle, R. L., DeMartini, E., \& Bowen, B. W. (2007). Genetic connectivity among color morphs and Pacific archipelagos for the flame angelfish, Centropyge loriculus. Marine Biology, 151(1), 167-175.

Streelman, J. T., Albertson, R. C., \& Kocher, T. D. (2007). Variation in body size and trophic morphology within and among genetically differentiated populations of the cichlid fish, Metriaclima zebra, from Lake Malawi. Freshwater Biology, 52(3), 525-538.

Tamura, K., Dudley, J., Nei, M., \& Kumar, S. (2007). MEGA4: Molecular evolutionary genetics analysis (MEGA) software version 4.0. Molecular Biology and Evolution, 24(8), 1596-1599.

Taylor, W. R., \& Van Dyke, G. C. (1985). Revised procedure for staining and clearing small fishes and other vertebrates for bone and cartilage study. Cybium, 9, 107-121.

Turelli, M., Barton, N. H., \& Coyne, J. A. (2001). Theory and speciation. Trends in Ecology \& Evolution, 16(7), 330-343.

Wainwright, P. C., \& Richard, B. A. (1995). Predicting patterns of prey use from morphology of fishes. Environmental Biology of Fishes, 44(1-3), 97-113.

Wright, S. (1951). The genetical structure of populations. The Annals of Eugenics, 15, 323-354.

Zelditch, M. L., Swiderski, D. L., Sheets, H. D., \& Fink, W. L. (2004). Geometric morphometrics for biologists: A primer (p. 443). San Diego: Elsevier Academic Press. 